This is the accepted manuscript of the following article: Fontenla, $F$., Blanco-Abad, V., Pardo, B.G., Folgueira, I., Noia, M., Gómez-Tato, A., Martínez, P., Leiro, J.M. \& Lamas J. (2016). Vaccine-induced modulation of gene expression in turbot peritoneal cells. A microarray approach.

Molecular Immunology, 75, 188-99. doi: 0.1016/j.molimm.2016.06.001. (C) $<$ Ano $>$ Elsevier B.V. This manuscript version is made available under the CC-BY-NC-ND 4.0 license (http://creativecommons.org/licenses/by-nc$n d / 4.0 /)$ 


\section{Vaccine-induced modulation of gene expression in turbot peritoneal cells. A microarray approach}

Francisco Fontenla ${ }^{1}$, Verónica Blanco-Abad ${ }^{1}$, Belén G. Pardo ${ }^{2}$, Iria Folgueira ${ }^{3}$, Manuel Noia ${ }^{1}$, Antonio Gómez-Tato ${ }^{4}$, Paulino Martínez ${ }^{2}$, José M. Leiro ${ }^{3}$, Jesús Lamas ${ }^{1} *$

${ }^{1}$ Departmento de Biología Celular y Ecología, Facultad de Biología (CIBUS), Rúa Lope Gómez de Marzoa, Universidad de Santiago de Compostela, 15782 Santiago de Compostela, Spain

${ }^{2}$ Departmento de Genética, Facultad de Veterinaria, Avda. Carballo Calero, Universidad de Santiago de Compostela, 27002 Lugo, Spain

${ }^{3}$ Departamento de Microbiología y Parasitología, Instituto de Investigación y Análisis Alimentarios, Rúa Constantino Candeira, Universidad de Santiago de Compostela, 15782 Santiago de Compostela, Spain

${ }^{4}$ Departmento de Geometría y Topología, Facultad de Matemáticas, Rúa Lope Gómez. de Marzoa, Universidad de Santiago de Compostela, 15782 Santiago de Compostela, Spain

*Corresponding author:

Dr J. Lamas

Tel: $+34-881816951$

Fax: +34-881813195

E-mail address: jesus.lamas@usc.es 


\begin{abstract}
We used a microarray approach to examine changes in gene expression in turbot peritoneal cells after injection of the fish with vaccines containing the ciliate parasite Philasterides dicentrarchi as antigen and one of the following adjuvants: chitosanPVMMA microspheres, Freund's complete adjuvant, aluminium hydroxide gel or Matrix-Q (Isconova, Sweden). We identified 374 genes that were differentially expressed in all groups of fish. Forty-two genes related to tight junctions and focal adhesions and/or actin cytoskeleton were differentially expressed in free peritoneal cells. The profound changes in gene expression related to cell adherence and cytoskeleton may be associated with cell migration and also with the formation of cellvaccine masses and their attachment to the peritoneal wall. Thirty-five genes related to apoptosis were differentially expressed. Although most of the proteins coded by these genes have a proapoptotic effect, others are antiapoptotic, indicating that both types of signals occur in peritoneal leukocytes of vaccinated fish. Interestingly, many of the genes related to lymphocytes and lymphocyte activity were downregulated in the groups injected with vaccine. We also observed decreased expression of genes related to antigen presentation, suggesting that macrophages (which were abundant in the peritoneal cavity after vaccination) did not express these during the early inflammatory response in the peritoneal cavity. Finally, several genes that participate in the inflammatory response were differentially expressed, and most participated in resolution of inflammation, indicating that an M2 macrophage response is generated in the peritoneal cavity of fish one day post vaccination.
\end{abstract}

\title{
Keywords
}

Turbot, microarray, vaccines, Philasterides dicentrarchi, peritoneal cells, gene expression 


\section{Introduction}

Injection of vaccines is the method that results in the best immune response and protection in fish (Lillehaug, 2014). Although vaccines can be administered via the intramuscular or intraperitoneal route, the latter is the most commonly used. Antigen by itself is usually poorly immunogenic and an adjuvant must be added to enhance the antigenicity (Tafalla at al., 2013). Most studies in fish injected with oil-based vaccines have evaluated the immune response generated (mainly by measuring the serum IgM levels) and the protection induced after experimental challenge. For example, in rainbow trout inoculated with a Yersinia ruckeri bacterin and the adjuvant Montanide ${ }^{\mathrm{TM}}$ ISA 763 A VG (Seppic), significantly enhanced serum IgM levels, increased numbers of $\operatorname{IgM}^{+}$cells in the spleen and significant upregulation of several immune genes in spleen, head kidney and liver were observed (Jaafar et al., 2015). Analysis of the immune response in salmonids suggests simultaneous expression of Th1, Th2, and Treg cytokines after administration of oil-based vaccines, with no clearly predominant response (Mutoloki et al., 2010; Kumari et al., 2013; Jaafar et al., 2015). Although aluminium-containing adjuvants are widely used in mammals, they are less commonly used in fish vaccines, probably because the immune response is narrower than that produced by the more commonly used oil-based adjuvants (Jiao et al., 2010). Very little is known about the immune responses generated by aluminium hydroxide adjuvants in fish, except in relation to the antibody levels generated and the protection induced. Although aluminium hydroxide-based adjuvants are generally considered to prime Th2type immune responses preferentially, more recent studies in mammals suggest that aluminium hydroxide-based adjuvants can enhance both Th1 and Th2 cellular responses, depending on the vaccination route (He et al., 2015). Several vaccines containing microspheres have been shown to induce activation of innate and adaptive immune responses in fish (Behera and Swain, 2012; Harikrishnan et al., 2012; LeónRodríguez et al., 2012, 2013), although there is no information about how these vaccines affect the activity of peritoneal cells or cells located in lymphoid organs. It is not known what takes place in the peritoneal cavity of fish after administration of a vaccine. Vaccination induces expression of inflammatory genes in lymphoid organs (Frediksen et al., 2011; Dan et al., 2013) and generation of Th1/Th2/Th17 immune responses has been suggested to occur; however, more sensitive tools are required to 
help us understand the type of response produced and thus enable more complex analysis of the immune response, comparable to that carried out in mammals.

Vaccines, particularly those containing oil-based adjuvants, can cause important lesions in the peritoneal cavity (Noia et al., 2014). The lesions, which include granulomas as well as adhesions between internal organs or between the organs and the peritoneal wall, vary depending on the adjuvant. Many of the free cells in the peritoneal cavity tend to adhere to the vaccine and thus form masses that become attached to the peritoneal wall. The cell-vaccine masses contain macrophage-like cells and apoptotic cells (Noia et al., 2014). Strong expression of genes related to cell-cell or cell-matrix adhesion and cell-cell junctions and also of genes related to actin cytoskeleton must occur in order to generate cell-vaccine masses. Differentiation, polarization, migration and adhesion processes are affected by the role of the cytoskeleton in innate immunity and cellular self-defence (Mostowy and Shenoy, 2015). In the present study, we used an oligo-microarray containing 43,803 spots and which is rich in genes involved in immunity and reproduction, but also in genes associated with cell adhesion and cytoskeleton (Ribas et al., 2013), to analyse the early cell response in the peritoneal cavity after vaccination. This is the first study of this type carried out in fish.

\section{Materials and methods}

\subsection{Fish}

Specimens of turbot Scophthalmus maximus (L.), of approximately $30 \mathrm{~g}$ body weight, were obtained from a local fish farm. The fish were maintained in 250-L tanks with aerated and recirculated sea water held at $16^{\circ} \mathrm{C}$ and were fed daily with commercial pellets. Fish were acclimatized to laboratory conditions for two weeks before the experiments began. All experimental protocols were approved by the Institutional Animal Care and Use Committee of the University of Santiago de Compostela (Spain). For all procedures, the fish were anaesthetized with benzocaine hydrochloride $(50 \mathrm{mg} / \mathrm{l})$ and killed by pithing.

\subsection{Philasterides dicentrarchi: culture and preparation of membrane antigen}

Philasterides dicentrarchi (isolate $\mathrm{C} 1$ ) was obtained from ascitic fluid of naturally infected turbot and maintained and cultured in the laboratory, as previously 
described (Piazzon et al., 2008). The membrane fraction of the ciliate was obtained as described in Budiño et al., (2012). Briefly, the ciliates $\left(1.5 \times 10^{7}\right)$ were resuspended in HEPES buffer containing dibucaine and incubated for $15 \mathrm{~min}$ at room temperature (to induce deciliation). After verification (by microscopic examination) that deciliation had occurred, the parasites were washed three times by centrifugation for $5 \mathrm{~min}$ at $600 \times \mathrm{g}$ in PBS at $4{ }^{\circ} \mathrm{C}$. The pellet containing the ciliates was then resuspended in PBS with $0.25 \mathrm{M}$ sucrose, disrupted ultrasonically and centrifuged at $8.000 \times \mathrm{g}$ for $5 \mathrm{~min}$. The pellet was dissolved in $3 \mathrm{ml}$ of HEPES buffer and added to a tube containing a sucrose gradient $(0.5 \mathrm{M}, 1 \mathrm{M}$ and $0.15 \mathrm{M})$. After centrifugation at $6.000 \times \mathrm{g}$, the $0.1 \mathrm{M}$ sucrose phase was removed and centrifuged at $11,000 \times \mathrm{g}$ for $20 \mathrm{~min}$. Finally, the pellet was resuspended in HEPES buffer with $0.5 \%$ Triton $\mathrm{X}-114$ for $15 \mathrm{~h}$ at $0^{\circ} \mathrm{C}$, to solubilise the membrane proteins. The suspension was centrifuged at $8.000 \times \mathrm{g}$ for $10 \mathrm{~min}$, and the supernatant was then concentrated by amicon ultrafiltration with $1 \mathrm{kDa}$ nominal molecular weight limit membranes (Millipore). The concentration of protein in the samples was determined by the Bradford method (Bio-Rad Protein Assay kit: Bio-Rad Laboratories, Germany), with BSA (Sigma-Aldrich, Spain) as standard. Philasterides dicentrarchi membrane proteins $(10 \mu \mathrm{g})$ were separated by SDS-PAGE on $10 \%$ linear polyacrylamide gels (Fig. S1), as previously described (Budiño et al., 2012).

\subsection{Vaccine preparation and administration}

Six groups of fish (in duplicate, 114 fish in total) were used. The control group $(\mathrm{n}=24)$ was injected intraperitoneally (i.p.) with $0.1 \mathrm{ml}$ of phosphate-buffered saline (PBS). The remaining groups ( $\mathrm{n}=18$ fish per group) were injected i.p. with $230 \mu \mathrm{g}$ of antigen in PBS, with $5 \mathrm{mg}$ of microspheres containing $230 \mu \mathrm{g}$ of covalently linked antigen to their surface in PBS (León-Rodríguez et al., 2012; Noia et al., 2014), or with a mixture of antigen and one of the following adjuvants (1:1, v:v): Freund's complete adjuvant (FCA), aluminium hydroxide gel (Alhydrogel, Sigma) or Matrix-Q (Isconova, Sweden) $(5 \mu \mathrm{g} / \mathrm{fish})$. Four of the fish in each of the duplicate control group and three of the fish in each of the other duplicate groups were then sampled at 1,3 and 5 days after injection.

To determine the effects of vaccination on serum antibody levels, six groups of fish (each $n=10$ ) were injected intraperitoneally (ip) on days 0 and 30 with $0.1 \mathrm{ml}$ of PBS, membrane antigen, or antigen and one of the following adjuvants: microspheres, 
Matrix-Q, Alhydrogel or Freund's, as indicated above. The water temperature was $17^{\circ} \mathrm{C}$. One month after the second dose, the serum antibody levels were determined in immunized fish. Blood samples for antibody analysis were obtained by caudal vein puncture and were allowed to clot for $16 \mathrm{~h}$ at $4^{\circ} \mathrm{C}$. The samples were then centrifuged and the serum was collected. The serum antibody levels were determined by double indirect enzyme-linked immunosorbent assay (ELISA), as described by Piazzon et al., (2008).

\subsection{Isolation of peritoneal cells}

Fish were bled by caudal vein puncture to prevent the presence of erythrocytes in the peritoneal cavity. The peritoneal cavity was then washed carefully with $5 \mathrm{~mL}$ of cold PBS and the cells were counted with a haemocytometer. Some cell samples were also smeared onto glass slides for staining with hemacolor (Merck) or diaminobenzidine (Sigma-Aldrich) (for peroxidase activity) and counterstained with haematoxylin, according to Kiernan (1981). Finally, the cell suspensions were washed twice with cold PBS by centrifugation at $300 \mathrm{x} \mathrm{g}$ for $5 \mathrm{~min}$, and the tubes containing the pellets were frozen in liquid nitrogen and held at $-80{ }^{\circ} \mathrm{C}$ until RNA extraction.

\subsection{RNA extractions and microarray hybridizations}

The stimulated cells were pelleted, and total RNA was extracted using the RNAeasy Mini kit (Qiagen) according to the manufacturer's recommendations. All extractions were performed by the same researcher. RNA quality and quantification were evaluated respectively in a Bioanalyzer (Bonsai Technologies) and in a NanoDrop ${ }^{\circledR}$ ND-1000 spectrophotometer (NanoDrop ${ }^{\circledR}$ Technologies Inc.), prior to labelling and hybridization. RNA extracted from peritoneal cells showed high quality parameters and all the samples had a RNA integrity higher than 8.9 and mostly above 9 .

A 4 x 44K Agilent oligo-microarray (43,840 spots corresponding to turbot transcripts and 1417 to Agilent controls) (Ribas et al 2013) was used to evaluate the gene expression profiles under the three conditions tested. The microarray platform Agilent-038160 was submitted to the Gene Expression Omnibus (GEO) repository under accession number GPL19564.

Twelve slides were used in the experiment, and samples from three or four groups of fish were included in each slide. One of the fish groups was always a PBS- 
127 injected group, and the others were various groups sampled at the same time as the control group. In total, 42 arrays were analysed. Hybridizations were performed by staff at the Agilent Technology Gene Expression Unit of the Functional Genomics Platform at the University of Santiago de Compostela (USC). Briefly, $50 \mathrm{ng}$ of total RNA was labelled using the Low Input Quick Amp Labeling Kit, One-Color (Cy3) (Agilent Technologies, USA). Copy RNA was hybridized overnight with the corresponding buffers for $17 \mathrm{~h}$ at $65^{\circ} \mathrm{C}$ and washed on the following day. Hybridized slides were scanned in an Agilent G2565B microarray scanner (Agilent Technologies, USA). All work was carried out on consecutive days and by the same researcher. The scanner images were segmented with the Agilent Feature and Agilent software was applied to prevent saturation in the highest intensity range. Agilent Feature Extraction produced the raw data for further pre-processing. The processed signal (gProcessed-Signal) value was the parameter chosen for the absolute hybridization signal, as recommended by Millán et al. (2011).

\subsection{Microarray analysis}

Microarray processing and filtration were performed as previously described (Millán et al., 2010; Domínguez et al., 2013). The signal was captured and processed in an Agilent scanner (G2565B, Agilent Technologies). The scanner images were segmented with Agilent Feature Extraction Software (v9.5) by applying the GE1-v5_95 protocol, which was used for obtaining raw and processed data. The processed signal (gProcessed-Signal) value was chosen for the statistical analysis. All microarrays were subjected to quality and filtering control before statistical analysis, following the criteria outlined by Millán et al., (2010). The data presented in this publication has been deposited in the NCBI's Gene Expression Omnibus (GEO, http://www.ncbi.nlm.nih.gov/geo/) and is available under accession number GSE82021. Normality of the log (lognormality) microarray signal (and gene signal) was assumed, and $\log _{2}$ transformation of the absolute signal or of the ratio treatment/control was therefore used in the statistical analysis. Normalization within each microarray was carried out by the LOESS method, which assumes that most genes in microarrays are not differentially expressed relative to the control. The mean $\log _{2}$ ratio for each gene was obtained by averaging the values obtained for both replicates per microarray. Two criteria were used simultaneously to identify differentially expressed genes (DEG): i) 
genes with $\log _{2}$ ratios $\geq 2$ or $\leq-2$ for up- and downregulated genes, respectively; and ii) genes that deviated from the null hypothesis (mean $\log _{2}$ ratio $=0$ ) (t-test at $\mathrm{P}<0.05$, after Bonferroni correction).

For comparison of the responses between groups, and to group closely related samples, the groups were clustered using an Agglomerative Hierarchy Method, implemented with the Cluster package in $\mathrm{R}$ statistical software. The results of hierarchical clustering are presented in a dendrogram. We compared the overall response for all groups, as well as the responses based on the biological functions of each gene (Gene Ontology: GO). We used the Blast2GO software (Conesa et al. 2005) and the AmiGO website http://amigo.geneontology.org/amigo/landing to analyse and study the enriched Gene Ontology (GO) terms in the genes that were differentially expressed between groups. Groups of DEG involved in a biological function were performed for hierarchical cluster, TreeView analyses and generation of heat maps using MultiExperiment Viewer (MeV) 4.9 software. KEGG pathway enrichment was assessed by DAVID Bioinformatics Database (Huang et al., 2009) with Danio rerio as background $(P<0.05)$. KEGG pathway analysis was performed to determine the involvement of DEG in different biological pathways. The analysis was carried out for all the groups of fish used and for each vaccinated group.

\subsection{Q-PCR microarray validation}

To validate microarray results by Q-PCR, we used a modified version of the random stratified procedure proposed by Mirón et al., (2006), as described by Millán et al., (2011). A set of 16 genes covering the range of variation in fold change (FC) across the different experimental conditions was selected (between -5.06 for C-C motif chemokine 20 in Matrix-Q at day one and 8.49 for claudin 1 in microspheres at day 5). The FCs of these genes in the 24 microarrays were ordered by FC value (16 genes $\times 42$ microarrays $=672$ cases $)$ and were stratified considering both the width and the abundance of values within each stratum. The gene-specific primers used in Q-PCR assays are shown in Table S1. Sets of FCs were selected at random within each stratum, completing 39 cases out of the 672 possible. Elongation factor 1-alpha was selected amongst the non-regulated genes and was used as housekeeping gene for Q-PCR analysis. The same RNA samples used for microarray hybridizations were used for Q- 
PCR. RNA ( $1 \mu \mathrm{g})$ was reverse transcribed into cDNA by using the AffinityScript Multiple Temperature cDNA Synthesis kit according to the supplier's protocol (Agilent Technologies). The Q-PCR analysis was carried out as previously described (Millán et al., 2011). For each gene, the fold change in transcript level was determined by the relative quantitative method $(\Delta \Delta \mathrm{Ct})$ (Livak and Schmittgen, 2001).

The results obtained in ELISA (serum antibody levels) were compared by analysis of variance (ANOVA) followed by Duncan's test. Differences were considered significant at $p<0.05$.

\section{Results and discussion}

201

\subsection{Cell dynamics in the peritoneal cavity after vaccination}

202

203

204

205

206

207

208

209

210

211

212

213

214

215

The four adjuvants induced migration of cells to the peritoneal cavity, with the number increasing on day 1 and then decreasing on days 3 and 5 (Fig. 1). The largest number of peritoneal free cells was found in groups of fish injected with vaccines containing Alhydrogel, FCA or microspheres, while Matrix-Q induced lower cell migration. The number of cells generated by injection of PBS or antigen alone was very low, although the latter induced a higher response. The variations in cell number with time are caused by cell migration to the peritoneal cavity as well as by attachment of free peritoneal cells to the peritoneal wall and migration to lymphomyeloid organs. Attachment of free peritoneal cells, particularly phagocytes, to the visceral and parietal peritoneum and migration of these cells to internal organs occurred very soon after injection, as they were detected after six hours in the spleen and kidney (Folgueira et al., 2015).

\subsection{Microarray validation by $Q-P C R$}

A total of 39 cases from 16 randomly selected genes covering most of the FC range in the study were used to validate the microarray data (Table S1). The number of cases analyzed per gene in different microarrays ranged from 2 to 4 due to the random selection approach used. All microarrays were validated using at least 4 genes, up to a maximum of 6 genes with an average of 5 genes/microarray. Elongation factor 1-alpha, the selected housekeeping gene, showed very low variation across the experimental 
221 conditions tested (CV: 0.026). We found a high correlation between Q-PCR and microarray expression values (Pearson $\rho$ coefficient $=0.78 ; \mathrm{P}=0$ ), indicating the consistency of our microarray data, as found in previous studies in turbot (Millán et al., 2010; 2011; Pardo et al., 2012).

\subsection{Analysis of differentially expressed genes}

In previous studies, we found that the total number of free peritoneal cells in turbot peaked very early after injection of particulate material and that by day 3 most of the cells with phagocytosed material were already attached to the peritoneum or migrated to other body areas (Noia et al., 2014; Folgueira et al., 2015). In the present study, we analyzed this early response (1, 3 and 5 days) in the peritoneal cells by measuring the changes in gene expression. We identified 374 genes that were differentially expressed across all groups of fish injected with vaccine (antigen and adjuvant) or with antigen alone and at the three times selected, relative to PBS injected fish (Fig. S2). Of these genes, 232 were upregulated, 133 were downregulated, and 12 were up- or downregulated, depending on the group or the time selected. The number of differentially expressed genes (DEG) varied depending on the adjuvant used: microspheres (284), Alhydrogel (255), FCA (234) and Matrix-Q (135) (Fig. 2). Only 65 DEG genes were identified in cells from fish injected with antigen alone; 12 of these were upregulated and the others were downregulated, although regulation was usually observed at only one time point.

GO terms were assigned to DEG, which were classified according to their function (Fig. 3). A large number of genes were involved in cell adhesion (between 8.9$14.7 \%$ of the total, depending on the group), actin cytoskeleton (4.2-8.1\%), cell surface receptors (9.6-12.3\%), cell proliferation (11.6-12.3\%), immune response (5.9-10.6\%), cell death (7.7-10.2) or cell migration (3.8-5.2\%). In comparison, the number of DEG involved in the inflammatory response was not particularly high (3.4-4.9\%). We estimated the similarity between pairs of adjuvant-treated groups by determining the Pearson's correlation coefficient $\rho$. We found very strong correlation between the FCA, Alhydrogel and microsphere-treated groups ( $\rho>0.98$ for all the combinations). The correlation between Matrix-Q and the other adjuvants was slightly lower, although still very high $(\rho>0.91-0.96)$. KEGG pathway analysis also showed that pathways related with extracellular matrix-receptor interaction, cell adhesion molecules, focal adhesion 
and regulation of actin cytoskeleton were among the top regulated ones (Fig.S3), supporting that free peritoneal cells are suffering profound changes related to cell adhesion and actin cytoskeleton.

\subsection{Vaccination increased expression of genes involved in cell adhesion and actin} cytoskeleton

The adjuvants tested induced differential expression in 42 genes related to cell junctions and focal adhesions and/or actin cytoskeleton organization (Fig. 4). Of these, 33 were upregulated, and the upregulation mainly occurred on day 5, except in the groups injected with microspheres, in which many of those genes were also regulated on days one and three. Claudin 1 (CLDN1), claudin 3A (CLDN3A), integrin 1-alpha (ITGA1), inverted formin (INF2), alpha-parvin (PARVAA), syndecan 3 (SDC3), cell adhesion associated oncogene regulated $(B O C)$, receptor-type tyrosine-protein phosphatase kappa $(P T P R K)$, cadherin $2(C D H 2)$ and E-cadherin $(C D H 1)$ are some of the genes that were upregulated in peritoneal cells of all the groups of fish injected with vaccine (Fig. 4). The increased expression of genes related to cell adhesion was correlated with the formation of groups of peritoneal cells in the peritoneal cavity after vaccination, which was observed in all groups of vaccinated fish at the three times selected (Fig. 5). Claudins are transmembrane proteins that participate in tight junctions between epithelial cells, but they have been reported to participate in tight junctions in other cell types, such as dendritic cells (Rescigno et al., 2001) and macrophages (Van den Bossche et al., 2012a). By using the tight junctions, dendritic cells can pass between epithelial cells without breaking the tight junction barrier. Expression of CLDN1 occurred in the peritoneal cells of all the groups of fish on days 1, 3 and 5, indicating continuous activation of this gene during several days. We also observed upregulation of $\mathrm{CDHl}$ on day 5. Although $\mathrm{CDHl}$ has been associated with maintenance of the epithelial barrier and regulation of epithelial cell function, it can also be express in dendritic cells, Langerhans cells, and macrophages (Van den Bossche et al., 2012b). Other genes involved in focal and adherent adhesions, such as ITGA1, BOC, CDH2, PTPRK and NCAM, were also upregulated on day 5 in all groups of fish injected with the vaccine, indicating that cell adhesion processes are strongly regulated in the peritoneal cells after vaccination. In previous studies, we have found that some 
peritoneal cells of vaccinated fish (especially macrophage-like cells) migrated to lymphoid organs, while others formed cell-vaccine masses in the peritoneal cavity with cells attached to each other and also to the mesothelium (Noia et al., 2014; Folgueira et al., 2015). The generation of tight and adherent junctions may cause the leukocytes to interact with the mesothelium or with other cells during the inflammatory response generated in the peritoneal cavity. Some genes involved in cell adhesion were slightly downregulated, e.g. the B-cell receptor CD22-like gene. This gene, which mediates B-B cell interactions, was downregulated on days one and three in the three groups but not in the group injected with Matrix-Q, probably reflecting the scarce number of B cells in the peritoneal cavity of injected fish, relative to controls.

In addition to the genes involved in cell adhesion, we observed a high level of regulation in genes related to the actin cytoskeleton. Upregulation of several genes involved in the dynamic turnover and restructuring of the actin cytoskeleton, such as inverted formin (INF2), parvin alpha (PARVA), profilin (PFN2), gelsolin (GSN) and others, indicates that this process is highly stimulated in peritoneal cells after injection of the vaccine. Adhesion, polarization and migration occur in leukocytes that migrate in and out of the peritoneum of fish injected with vaccine, and these processes require rearrangement of the actin cytoskeleton. Genes such as PARVA link cell adhesion with the actin cytoskeleton and are involved in focal adhesions facilitating association between integrins and actin. The actin cytoskeleton has important functions in leukocyte activities, including cell signalling, adhesion, migration and phagocytosis (Rougerie et al., 2013; Schnoor, 2015), and it is also a sensor of extracellular stimuli and regulator of transcriptional activation of genes involved in other leukocyte activities (Taylor and Halene, 2015). The profound cytoskeletal changes that occurred in free peritoneal cells of stimulated immunized fish may also affect other activities related to cell activation. Apart from migration to lymphoid organs, upregulation of many genes related to cytoskeleton and cell adhesion may also be related to the formation of cell-vaccine masses in the peritoneal cavity and to the attachment of those masses to the peritoneal wall. In previous studies, we have found that all the adjuvants caused some internal adhesions, although these were more apparent for FCA and less evident for microspheres, aluminium hydroxide and Matrix-Q (Noia et al., 2014). However, we did not observe a clear relationship between the levels of gene expression induced by the adjuvants in peritoneal cells and the damage generated in the cavity. As mentioned in 
the previous study, other adjuvant properties such as viscosity may have a greater influence on the size of the cell-vaccine masses and the formation of internal adhesions.

\subsection{Regulation of apoptosis}

Thirty-one genes related to apoptosis were differentially expressed, and six of these were upregulated in all groups, which mainly included genes that were highly expressed. The others included 16 upregulated and 9 downregulated genes in most, although not all, of the groups (Fig. 6). The upregulated genes included 24dehydrocholesterol reductase (DHCR24), caspase 8 (CASP8), complement component 6-like (C6), transglutaminase $2 \mathrm{~b}(T G 2)$, retinoic acid receptor alpha (RARA), amyloid beta (A4) precursor-like protein (APLP1), PRKC, apoptosis, WT1, regulator (PAWR) and adenosine A2a receptor (ADORA2A); others were downregulated, including the gene coding for death-associated protein-like 1-A (DAPL1). Some of these genes have a proapoptotic effect but others are antiapoptotic, so that both types of signals probably occur in peritoneal leukocytes of vaccinated fish. Genes with a positive effect on apoptosis include CASP8, an initiator caspase involved in death receptor-mediated apoptosis stimulated by FasL, TNF $\alpha$ or tumour necrosis factor-related apoptosisinducing ligand (Mocarski et al., 2011; Monie and Bryant, 2015); TG2, a multifunctional gene that has been implicated in apoptotic cell clearance (Nadella et al., 2015); and RARA, which has been associated with neutrophil differentiation and apoptosis (Kastner and Chan, 2001). Among the genes related to anti-apoptotic activity, we observed upregulation of those coding for DHCR24, a gene that when is overexpressed can protect the cells from apoptosis induced by oxidative stress (Lu et al., 2008), A4, which delays the apoptotic rate of human neutrophils (Park et al., 2006), and ADORA2A, which induces a delay in spontaneous apoptosis of human neutrophils (Pliyeb et al., 2014). Vaccines containing the same adjuvants as tested in the present study induced generation of numerous apoptotic neutrophils in the peritoneal cavity of turbot (Noia et al., 2014). However, migration of inflammatory neutrophils from the peritoneal cavity to lymphoid organs after injection of an inflammatory stimulus has been described in fish (Chaves-Pozo et al., 2005). The presence of apoptotic and antiapoptotic stimuli is necessary in order to generate apoptosis in some cells and to maintain the rate of apoptosis at certain levels and to induce cell migration and release of inflammatory cytokines, as described in mammals (Hofman, 2004). 

downregulated

Interestingly, many of the genes associated with lymphocytes and lymphocyte activity were downregulated in the groups injected with vaccines containing microspheres, FCA and Alhydrogel (Fig. 7). The downregulation affected a smaller number of genes in the group injected with vaccine containing Matrix-Q. Some of the downregulated genes included chemokines such as $\mathrm{CC}$ chemokine (C-C motif) 20/Macrophage Inflammatory Protein-3 (CCL2O), which plays an important role in the constitutive trafficking of leukocytes, including immature dendritic cells and $\mathrm{T}$ and $\mathrm{B}$ lymphocytes (Zhao et al., 2014), and chemokine (C-C motif) ligand 4 /macrophage inflammatory protein-1 $\beta$ (CCL4), which participates in the migration of immune cells, and blockage of this chemokine reduced T-cell migration to lymph nodes after vaccination (Castellino et al., 2006). Fish studies have shown that CCL4 attracts leukocytes, induces an inflammatory response and drives lymphocyte differentiation in the Th1 pathway (Hsu et al., 2013). Other downregulated genes included those coding for chemokine (C-C motif) receptor $7(C C R 7)$ and chemokine (C-C motif) receptor 9 (CCR9), both of which are expressed in lymphocytes in mammals and fish (Kim, 2005; Castro et al., 2014); transcription factor 7 (T-Cell Specific, HMG-Box) and T-cell receptor beta, which are expressed in $\mathrm{T}$ cells. We also observe a decrease in the expression of genes coding for proteins expressed in B cells, such as B-cell CLL/lymphoma $11 \mathrm{Ab}$, immunoglobulin heavy variable 4-31, immunoglobulin gamma 2A chain, lymphocyte antigen 6 complex, locus G6F, B-cell receptor CD22, immunoglobulin mu heavy chain, and B-cell antigen receptor complex-associated protein alpha chain. These results indicate that genes related to $\mathrm{B}$ and $\mathrm{T}$ lymphocyte activity and migration were inhibited in peritoneal cells after injection of vaccine and contrast with those found in the spleen of Asian sea bass, where up-regulation of genes related to lymphocytes was observed on days one and seven after vaccination (Jiang et al., 2014). It has been shown that the peritoneal cavity of vaccinated turbot has low levels of lymphocytes in comparison with other cell types (Folgueira et al., 2015). The decrease in the production of chemokines that attract lymphocyte would decrease the lymphocyte population and because there are few lymphocytes we found very low expression of lymphocyte markers. We have also found important differences between vaccines containing Matrix-Q and the vaccines containing the other adjuvants. Matrix-Q 
only induced downregulation of 4 genes (CCR7, TCF7, CCLA, CCL20) and at a much lower level than the other adjuvants, indicating that this adjuvant has a lower inhibitory effect on lymphocyte activity and migration than the others.

In fish injected with vaccines containing microspheres, FCA or Alhydrogel, we observed decreased expression of genes related to antigen presentation, such as MHC class II antigen alpha chain (MHCIIa) and gamma-interferon-inducible lysosomal thiol reductase (GILT) (Fig. 7). GILT is constitutively expressed in antigen presenting cells in mammals and catalyzes disulphide bond reduction that may be important for generation of class II epitopes (Phan et al., 2000). MHCII is also expressed in antigen presenting cells, such as dendritic cells, macrophages and B cells. The number of peritoneal macrophages in the cavity was high at the times used in the present and a previous study (Folgueira et al., 2015). However, these macrophages did not appear to express these genes during this early inflammatory response in the peritoneal cavity, suggesting that many of the free macrophages were $\mathrm{MHCII}^{-}$. Most of the inflammatory macrophages during acute peritonitis in mice were $\mathrm{MHCII}^{-}$, while all the migratory macrophages in lymph nodes were $\mathrm{MHCII}^{+}$(Gautier et al., 2013). Something similar may occur in fish, in which MHCII expression may increase during migration to lymphoid organs or in areas of cell-vaccine masses.

\subsection{Regulation of the inflammatory response}

Several genes that participate in the inflammatory response were differentially expressed. Some of them had a positive effect on induction of inflammation, although the majority participate in their resolution. Expression of interleukin 6 receptor (IL6R) increased on day one, except in the group injected with Matrix-Q (Fig. 8). IL6 exhibits pro-inflammatory and anti-inflammatory properties, plays a central role in host defence against infection and tissue injury, and differentially regulates the expression of inflammatory chemokines including interleukin 8 (CXCL8/IL8) and chemokine (C-C motif) ligand 2 as well as neutrophil migration to inflamed sites. However, soluble IL6R-mediated signalling is an important intermediary in the resolution of inflammation and supports the transition between the early predominantly neutrophilic stage of an infection and the more sustained mononuclear cell influx (Hurst et al., 2001). Very few proinflammatory cytokines were upregulated in peritoneal cells of vaccinated turbot. CXCL8 was upregulated in the groups injected with aluminium or with matrix-Q, and 
tumour necrosis factor alpha was upregulated in one group and only at one time point. The TNF receptor-associated factor 4 was upregulated on day 5 in the groups injected with FCA or with microspheres. However, several genes associated with resolution of the inflammatory response were regulated. This is the case with $C D H 1$, a gene that was upregulated in all groups, which has been associated with M2 macrophage activation in mammals, inducing suppression of the inflammatory response (Van den Bossche et al., 2012b). Similarly, upregulation of CLDN1 expression occurred in the peritoneal cells of all the groups of fish on days 1, 3 and 5, indicating continuous activation of this gene over several days. CLDN1 expression has also been associated with TGF- $\beta$ activated M2 macrophages (Van den Bossche et al., 2012a). We also observed upregulation of $A D O R A 2 A$ in the cells of all three groups injected with vaccine and annexin A1 $(A N X A 1)$ in the group injected with microspheres. Adenosine signalling promotes the induction of M2 activation via adenosin receptors (Ferrante et al., 2013). ANXA1 is a protein with potent anti-inflammatory activity (Perretti and D'Acquisto, 2009). Another sign of M2 polarisation is the upregulation of several scavenger receptors able to bind a diverse array of endogenous and foreign molecules (Peiser and Gordon, 2001), and we observed upregulation of scavenger receptor class B, an LDL receptor, in all groups of fish injected with vaccine and of mannose receptor in some groups. Finally, we also observed upregulation of peroxisome proliferator-activated receptor gamma (PPARG) also occurred in all groups on day one. The PPARG ligand has been shown to exert potent anti-inflammatory effects in mammals, promoting apoptosis of neutrophils and reducing macrophage inflammatory activation while enhancing phagocytosis. In addition, $P P A R G$ is the main member of the PPAR family in promoting M2 macrophages (Croasdell et al., 2015).

We also observed downregulation of genes related to antigen presentation such as MCHIIa, and of molecules related to antigen processing, such as GILT (Fig. 7). Antigen presentation is crucial for the generation of protective T-cell responses against pathogens and for later $\mathrm{T}$ cell-dependent activation of the $\mathrm{B}$ cells and for antibody production. Decreased antigen presentation and an overall suppressive response has also been associated with the M2 macrophage response (Moser, 2003), and certain cytokines characteristic of $\mathrm{M} 2$ response can also downregulate $M H C I I$ expression and antigen presentation (de Waal Malefyt et al., 1991). M2 macrophages can be further divided into several phenotypes based on gene expression profiles in mammals, and these phenotypes seem to be present in fish (Hodgkinson et al., 2015). The macrophage states 
can be induced by several cytokines, such as IL4 or IL13, or the macrophages themselves can produce certain cytokines such as IL10. Unfortunately, those cytokines were not included in the microarray and therefore it was not possible to determine their expression levels. It is therefore difficult to suggest which subsets of M2 macrophages dominate in this response. Nonetheless, analysis of the microarray suggests that the resolution of inflammatory reaction had already started at one day after injection in all the groups of vaccinated turbot, and that this effect was more marked in the group injected with microspheres and was less evident in the group injected with Matrix-Q. Resolution of acute inflammation involves the cessation of PMN trafficking, proinflammatory mediator catabolism, apoptosis and phagocytosis, collectively allowing stromal cells and parenchymal tissues of the injured site to resume their normal physiological function. Resolution of inflammation has been observed to be initiated within 6 hours in mammalian models of acute self-limited inflammatory response to carrageenan and zymosan (Bannenberg et al., 2005). Our results indicate that this process can also be activated early on in fish.

\subsection{Comparison of the gene expression responses between groups}

We compared the different vaccinated groups, in order to relate the changes in the peritoneal cells to the administration of a particular adjuvant. The overall response in the groups injected with antigen alone was similar at the three times tested and was also similar to the response on days 1 and 3 post injection in groups injected with antigen plus Matrix-Q. The responses in the other groups were more dependent on the time after infection than on the adjuvant administered (Fig. 9). On day 5, all the adjuvanted vaccines generated a similar response, although the groups injected with 472 microspheres and FCA were more closely related than the groups injected with 473 Alhydrogel and Matrix-Q. Interestingly, this pattern of response was similar when groups were compared in relation to genes whose expression is related to cytoskeleton reorganization, cell adhesion, apoptosis, angiogenesis or cell migration (Figs. S3 and S4). With the exception of Matrix-Q, the response to which was more similar to the response to antigen alone on days 1 and 3, the associations found in the other groups were primarily related to the time since injection and secondarily to the adjuvant used. The transcriptomic response induced by antigen alone was very low compared with that induced by antigen and adjuvant, and very similar to that induced by PBS, indicating 
481 that the response generated is more closely related to the adjuvant used than to the 482 antigen.

483

484

485

486

487

488

489

490

491

492

493

494

495

496

497

498

499

500

501

502

503

504

505

506

507

508

509

510

\subsection{Comparison between gene expression in peritoneal cells and serum antibody levels}

In parallel with the microarray experiment, we evaluated the antibody responses generated in turbot after vaccination with the same antigens and adjuvants used in the gene expression experiment. The microarray analysis showed that Alhydrogel, Freund's and microspheres induced a very similar cell migration and gene expression response in free peritoneal cells. However, the antibody response generated by Freund's was much higher than that induced by the other adjuvants (Fig. 10). Fish injected with Matrix-Q, Alhydrogel or microspheres showed similar antibody levels, although the former was less inflammatory. There are several possible reasons explaining these discrepancies. The immune response generated by vaccines is more closely related to the events that take place in the cell-vaccine masses and in the immune organs rather than in free peritoneal cells. Other effects, such as the depot effect, are also probably important in generating antibody production, as shown in mammals (Batista-Duharte et al., 2013).

\subsection{Conclusions}

The study findings provide new information about the early gene expression responses in free peritoneal cells of vaccinated turbot. Although antigen alone had little effect on cell migration and gene expression levels, in comparison with PBS injected fish, the four adjuvants tested (Alhydrogel ${ }^{\circledR}$, FCA, microspheres and Matrix-Q ${ }^{\circledR}$ ) strongly induced activation of genes involved in cell adhesion and actin cytoskeleton, induced pro- and anti-apoptotic signals, downregulated genes related to lymphocyte migration and activity and also increased the expression of a number of genes involved in resolution of the inflammatory response. Matrix-Q induced lower cell migration and gene expression levels than the other three adjuvants, which generated very similar responses. Interestingly, we also observed decreased expression of genes involved in antigen presentation, indicating that this process does not occur in free peritoneal cells. Finally, we did not observe any relationship between gene expression in peritoneal cells and serum antibody levels in vaccinated fish. The latter is probably more closely related to the events occurring in the cell-vaccine masses generated in the peritoneal cavity and 
511 in lymphoid organs. However, further research is necessary in order to clarify the 512 relationship.

Acknowledgements

515

This study was financially supported by the Ministerio de Economía y Competitividad (Spain) under grant agreement AGL2014-57125-R and by the Xunta de

517 Galicia (Spain) under grant agreement GPC2014/069. The project received funding 518 from the European Union's Horizon 2020 research and innovation programme under 519 grant agreement No. 634429. This publication reflects the views of the authors, and the 520 European Commission cannot be held responsible for any use that may be made of the 521 information contained therein. The authors thank Andrés Blanco for help with the 522 bioinformatics analysis.

\section{References}

524 Bannenberg, G.L., Chiang, N., Ariel, A., Arita, M., Tjonahen, E., Gotlinger, K.H., Hong, S., Serhan, C.N., 2005. Molecular circuits of resolution, Formation and actions of resolvins and protectins. J. Immunol. 174,4345-4355.

Batista-Duharte, A., Portuondo, D., Carlos, I.Z., Pérez, O., 2013. An approach to local immunotoxicity induced by adjuvanted vaccines. Int Immunopharmacol. 17, 526-536.

Behera, T., Swain, P., 2012. Antigen adsorbed surface modified poly-varepsiloncaprolactone microspheres stimulates both adaptive and innate immune response in fish. Vaccine 30,5278-5284.

Budiño, B., Leiro, J., Cabaleiro, S., Lamas, J., 2012. Characterization of Philasterides dicentrarchi isolates that are pathogenic to turbot: Serology and cross-protective immunity. Aquaculture 364-365,130-136.

Castellino, F., Huang, A.Y., Altan-Bonnet, G., Stoll, S., Scheinecker, C., Germain, R.N., 2006. Chemokines enhance immunity by guiding naive $\mathrm{CD}^{+} \mathrm{T}$ cells to sites of $\mathrm{CD}^{+}{ }^{+} \mathrm{T}$ cell-dendritic cell interaction. Nature 440,890-895.

Castro, R., Bromage, E., Abos, B., Pignatelli, J., Gonzalez Granja, A., Luque, A., Tafalla, C., 2014. CCR7 is mainly expressed in teleost gills, where it defines an $\operatorname{IgD}^{+} \operatorname{IgM}^{-}$B lymphocyte subset. J. Immunol. 192,1257-1266. 
Chaves-Pozo, E., Munoz, P., Lopez-Muñoz, A., Pelegrin, P., Garcia Ayala, A., Mulero, V., Meseguer, J., 2005. Early innate immune response and redistribution of inflammatory cells in the bony fish gilthead seabream experimentally infected with Vibrio anguillarum. Cell Tissue Res. 320,61-68.

Conesa, A., Gotz, S., Garcia-Gomez, J.M., Terol, J., Talon, M., Robles, M., 2005. Blast2GO, A universal tool for annotation, visualization and analysis in functional genomics research. Bioinformatics 21,3674-3676.

Croasdell, A., Duffney, P.F., Kim, N., Lacy, S.H., Sime, P.J., Phipps, R.P., 2015. PPARgamma and the innate immune system mediate the resolution of inflammation. PPAR Res 2015,549691.

Dan, X.M., Zhang, T.W., Li, Y.W., Li, A.X., 2013. Immune responses and immunerelated gene expression profile in orange-spotted grouper after immunization with Cryptocaryon irritans vaccine. Fish Shellfish Immunol. 34,885-891.

de Waal Malefyt, R., Haanen, J., Spits, H., Roncarolo, M.G., de Velde, A., Figdor, C., Johnson, K., Kastelein, R., Yssel, H., de Vries, J.E. 1991. Interleukin 10 (IL-10) and viral IL-10 strongly reduce antigen-specific human $\mathrm{T}$ cell proliferation by diminishing the antigen-presenting capacity of monocytes via downregulation of class II major histocompatibility complex expression. J. Exp. Med. 174,915-924.

Dominguez, B., Pardo, B.G., Noia, M., Millan, A., Gomez-Tato, A., Martinez, P., Leiro, J., Lamas, J., 2013. Microarray analysis of the inflammatory and immune responses in head kidney turbot leucocytes treated with resveratrol. Int. Immunopharmacol. 15,588-596.

Ferrante, C.J., Pinhal-Enfield, G., Elson, G., Cronstein, B.N., Hasko, G., Outram, S., Leibovich, S.J., 2013. The adenosine-dependent angiogenic switch of macrophages to an M2-like phenotype is independent of interleukin-4 receptor alpha (IL-4Ralpha) signaling. Inflammation 36,921-931.

Folgueira, I., Noia, M., Blanco-Abad, V., Mallo, N., Leiro, J., Lamas, J., 2015. Particle size and traffic of phagocytes between the turbot peritoneal cavity and lymphoid organs. Fish Shellfish Immunol. 44,652-661.

Fredriksen, B.N., Saevareid, K., McAuley, L., Lane, M.E., Bogwald, J., Dalmo, R.A., 2011. Early immune responses in atlantic salmon (Salmo salar L.) after immunization with PLGA nanoparticles loaded with a model antigen and betaglucan. Vaccine 29,8338-8349. 
575 Gautier, E.L., Ivanov, S., Lesnik, P., Randolph, G.J., 2013. Local apoptosis mediates clearance of macrophages from resolving inflammation in mice. Blood $122,2714-2722$.

Harikrishnan, R., Balasundaram, C., Heo, M.S., 2012. Poly D,L-lactide-co-glycolic acid (PLGA)-encapsulated vaccine on immune system in Epinephelus bruneus against Uronema marinum. Exp. Parasitol. 131,325-332.

He, P., Zou, Y., Hu, Z., 2015. Advances in aluminum hydroxide-based adjuvant research and its mechanism. Hum. Vaccin. Immunother. 11,477-488.

Hodgkinson, J.W., Grayfer, L., Belosevic, M., 2015. Biology of bony fish macrophages. Biology (Basel) 4,881-906.

Hofman, P., 2004. Molecular regulation of neutrophil apoptosis and potential targets for therapeutic strategy against the inflammatory process. Curr. Drug Targets Inflamm. Allergy 3,1-9.

Hsu, Y.J., Hou, C.Y., Lin, S.J., Kuo, W.C., Lin, H.T., Lin, J.H., 2013. The biofunction of orange-spotted grouper (Epinephelus coioides) CC chemokine ligand 4 (CCL4) in innate and adaptive immunity. Fish Shellfish Immunol. 35,18911898.

Huang da, W., Sherman, B.T., Lempicki, R.A., 2009. Systematic and integrative analysis of large gene lists using DAVID bioinformatics resources. Nat. Protoc. 4,44-57.

Hurst, S.M., Wilkinson, T.S., McLoughlin, R.M., Jones, S., Horiuchi, S., Yamamoto, N., Rose-John, S., Fuller, G.M., Topley, N., Jones, S.A., 2001. Il-6 and its soluble receptor orchestrate a temporal switch in the pattern of leukocyte recruitment seen during acute inflammation. Immunity 14,705-714.

Jaafar, R.M., Chettri, J.K., Dalsgaard, I., Al-Jubury, A., Kania, P.W., Skov, J., Buchmann, K., 2015. Effects of adjuvant montanide ISA 763 A VG in rainbow trout injection vaccinated against Yersinia ruckeri. Fish Shellfish Immunol. 47,797-806.

Jiang, J., Miyata, M., Chan, C., Ngoh, S.Y., Liew, W.C., Saju, J.M., Ng, K.S., Wong, F.S., Lee, Y.S., Chang, S.F., et al. 2014. Differential transcriptomic response in the spleen and head kidney following vaccination and infection of asian seabass with Streptococcus iniae. PLoS One 9,e99128. 
Jiao, X.D., Cheng, S., Hu, Y.H., Sun, L., 2010. Comparative study of the effects of aluminum adjuvants and freund's incomplete adjuvant on the immune response to an Edwardsiella tarda major antigen. Vaccine 28,1832-1837.

Kastner, P., Chan, S., 2001. Function of RARalpha during the maturation of neutrophils. Oncogene 20,7178-7185.

Kiernan, J.A., 1981. Histological and histochemical methods. Oxford: Pergamon Press.

Kim, C.H., 2005. The greater chemotactic network for lymphocyte trafficking: Chemokines and beyond. Curr. Opin. Hematol. 12,298-304.

Kumari, J., Bogwald, J., Dalmo, R.A., 2013. Vaccination of atlantic salmon, Salmo salar L., with Aeromonas salmonicida and infectious pancreatic necrosis virus (IPNV) showed a mixed Th1/Th2/Treg response. J. Fish Dis. 36,881-886.

Leon-Rodriguez, L., Luzardo-Alvarez, A., Blanco-Mendez, J., Lamas, J., Leiro, J., 2012. A vaccine based on biodegradable microspheres induces protective immunity against scuticociliatosis without producing side effects in turbot. Fish Shellfish Immunol. 33,21-27.

Leon-Rodriguez, L., Luzardo-Alvarez, A., Blanco-Mendez, J., Lamas, J., Leiro, J., 2013. Biodegradable microparticles covalently linked to surface antigens of the scuticociliate parasite $P$. dicentrarchi promote innate immune responses in vitro. Fish Shellfish Immunol. 34,236-243.

Lillehaug, A., 2014. Vaccination strategies and procedures. In: Fish Vaccination. Gudding, R., Lillehaug, A., Evensen, O., editors. Chichester, UK: John Wiley \& Sons Ltd.

Livak, K.J., Schmittgen, T.D., 2001. Analysis of relative gene expression data using real-time quantitative PCR and the 2(-delta delta $\mathrm{C}(\mathrm{T})$ ) method. Methods 25,402-438.

Lu, X., Kambe, F., Cao, X., Kozaki, Y., Kaji, T., Ishii, T., Seo, H., 2008. 3betahydroxysteroid-delta24 reductase is a hydrogen peroxide scavenger, protecting cells from oxidative stress-induced apoptosis. Endocrinology 149,3267-3273.

Millan, A., Gomez-Tato, A., Fernandez, C., Pardo, B.G., Alvarez-Dios, J.A., Calaza, M., Bouza, C., Vazquez, M., Cabaleiro, S., Martinez, P.. 2010. Design and performance of a turbot (Scophthalmus maximus) oligo-microarray based on ESTs from immune tissues. Mar. Biotechnol. (NY) 12,452-465.

Millan, A., Gomez-Tato, A., Pardo, B.G., Fernandez, C., Bouza, C., Vera, M., AlvarezDios, J.A., Cabaleiro, S., Lamas, J., Lemos, M.L., et al. 2011. Gene expression 
profiles of the spleen, liver, and head kidney in turbot (Scophthalmus maximus) along the infection process with Aeromonas salmonicida using an immuneenriched oligo-microarray. Mar. Biotechnol. (NY) 13,1099-1114.

Miron, M., Woody, O.Z., Marcil, A., Murie, C., Sladek, R., Nadon, R., 2006. A methodology for global validation of microarray experiments. BMC Bioinformatics 7,333.

Mocarski, E.S., Upton, J.W., Kaiser, W.J., 2011. Viral infection and the evolution of caspase 8-regulated apoptotic and necrotic death pathways. Nat. Rev. Immunol. $12,79-88$.

Monie, T.P., Bryant, C.E., 2015. Caspase- 8 functions as a key mediator of inflammation and pro-IL-1beta processing via both canonical and non-canonical pathways. Immunol. Rev. 265,181-193.

Mosser, D.M., 2003. The many faces of macrophage activation. J. Leukoc. Biol. 73,209-212.

Mostowy, S., Shenoy, A.R., 2015. The cytoskeleton in cell-autonomous immunity: Structural determinants of host defence. Nat. Rev. Immunol. 15,559-573.

Mutoloki, S., Cooper, G.A., Marjara, I.S., Koop, B.F., Evensen, O., 2010. High gene expression of inflammatory markers and IL-17A correlates with severity of injection site reactions of atlantic salmon vaccinated with oil-adjuvanted vaccines. BMC Genomics 11,336

Nadella, V., Wang, Z., Johnson, T.S., Griffin, M., Devitt, A., 2015. Transglutaminase 2 interacts with syndecan-4 and CD44 at the surface of human macrophages to promote removal of apoptotic cells. Biochim. Biophys. Acta 1853,201-212.

Noia, M., Dominguez, B., Leiro, J., Blanco-Mendez, J., Luzardo-Alvarez, A., Lamas, J., 2014. Inflammatory responses and side effects generated by several adjuvantcontaining vaccines in turbot. Fish Shellfish Immunol. 38,244-254.

Pardo, B.G., Millan, A., Gomez-Tato, A., Fernandez, C., Bouza, C., Alvarez-Dios, J.A., Cabaleiro, S., Lamas, J., Leiro, J.M., Martinez, P., 2012. Gene expression profiles of spleen, liver, and head kidney in turbot (Scophthalmus maximus) along the infection process with Philasterides dicentrarchi using an immuneenriched oligo-microarray. Mar. Biotechnol. (NY) 14,570-582.

Park, H.Y., Park, J.I., Baek, D.W., Lee, S.Y., Lee, M.J., Jin, J.O., Kim, J.W., Hong, Y.S., Lee, Y.H., Kwak, J.Y., 2006. Modulation of neutrophil apoptosis by betaamyloid proteins. Int. Immunopharmacol. 6,1061-1069. 
Peiser, L., Gordon, S., 2001. The function of scavenger receptors expressed by macrophages and their role in the regulation of inflammation. Microbes Infect. 3,149-159.

Perretti, M., D'Acquisto, F., 2009. Annexin A1 and glucocorticoids as effectors of the resolution of inflammation. Nat. Rev. Immunol, 9,62-70.

Phan, U.T., Arunachalam, B., Cresswell, P.. 2000. Gamma-interferon-inducible lysosomal thiol reductase (GILT). maturation, activity, and mechanism of action. J. Biol. Chem. 275,25907-25914.

Piazzon, C., Lamas, J., Castro, R., Budiño B., Cabaleiro, S., Sanmartin, M., Leiro, J., 2008. Antigenic and cross-protection studies on two turbot scuticociliate isolates. Fish Shellfish Immunol. 25,417-424.

Pliyev, B.K., Dimitrieva, T.V., Savchenko, V.G., 2014. Diadenosine diphosphate $(\operatorname{ap}(2) \mathrm{A})$ delays neutrophil apoptosis via the adenosine $\mathrm{A} 2 \mathrm{~A}$ receptor and cAMP/PKA pathway. Biochem. Cell. Biol. 92,420-424.

Rescigno, M., Urbano, M., Valzasina, B., Francolini, M., Rotta, G., Bonasio, R., Granucci, F., Kraehenbuhl, J.P., Ricciardi-Castagnoli, P., 2001. Dendritic cells express tight junction proteins and penetrate gut epithelial monolayers to sample bacteria. Nat. Immunol. 2,361-367.

Ribas, L., Pardo, B.G., Fernandez, C., Alvarez-Dios, J.A., Gomez-Tato, A., Quiroga, M.I., Planas, J.V., Sitja-Bobadilla, A., Martinez, P., Piferrer, F., 2013. A combined strategy involving sanger and 454 pyrosequencing increases genomic resources to aid in the management of reproduction, disease control and genetic selection in the turbot (Scophthalmus maximus). BMC Genomics 14,180.

Rougerie, P., Miskolci, V., Cox, D., 2013. Generation of membrane structures during phagocytosis and chemotaxis of macrophages. Role and regulation of the actin cytoskeleton. Immunol. Rev. 256,222-39.

Schnoor, M., 2015. Endothelial actin-binding proteins and actin dynamics in leukocyte transendothelial migration. J. Immunol. 194,3535-3541.

Tafalla, C., Bogwald, J., Dalmo, R.A., 2013. Adjuvants and immunostimulants in fish vaccines: Current knowledge and future perspectives. Fish Shellfish Immunol. 35,1740-1750.

Taylor, A., Halene, S., 2015. The regulatory role of serum response factor pathway in neutrophil inflammatory response. Curr. Opin. Hematol. 22,67-73. 


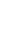

Van den Bossche, J,. Laoui, D., Morias, Y., Movahedi, K., Raes, G., De Baetselier, P., Van Ginderachter, J.A., 2012a. Claudin-1, claudin-2 and claudin-11 genes differentially associate with distinct types of anti-inflammatory macrophages in vitro and with parasite- and tumour-elicited macrophages in vivo. Scand. J. Immunol. 75,588-598.

Van den Bossche, J., Malissen, B., Mantovani, A., De Baetselier, P., Van Ginderachter, J.A., 2012b. Regulation and function of the E-cadherin/catenin complex in cells of the monocyte-macrophage lineage and DCs. Blood 119,1623-1633.

Zhao, L., Xia, J., Wang, X., Xu, F., 2014. Transcriptional regulation of CCL20 expression. Microbes Infect. 16,864-870. 
Fig.1. Number of free cells in the peritoneal cavity of fish injected with PBS, antigen or with vaccines containing antigen and different adjuvants, on days 0, 1, 3 and 5 post injection. Results are presented as means \pm S.E.M; $n=6 /$ group, with the exception of the PBS and control 0h groups $(n=8)$.

Fig. 2. Venn diagram showing the total number of upregulated (red) and downregulated (green) genes at the three sampling times in the groups injected with antigen and adjuvant, in comparison with PBS injected groups.

Fig. 3. Pie charts showing the proportion (\%) of DEG by biological function in peritoneal cells from fish injected with a vaccine containing antigen and one of the four adjuvants tested. Genes can be differentially expressed at one or more sampling times.

Fig. 4. Heat map displaying hierarchical clustering of DEG involved in cell adhesion and cytoskeleton. Data are from fish injected with antigen (Ant) or with antigen plus adjuvant (Alhydrogel [Al], Freund's [FCA], Matrix-Q [MQ] or microspheres [Mic]), on days 1, 3 and 5 after injection. Results are expressed as mean expression ratio (log2- of different groups vs PBS). Red indicates increased gene expression levels; green indicates decreased levels.

Fig. 5. Peritoneal cells of fish vaccinated with antigen and Freund's adjuvant at 1 (A), 3 (B) and 5 (C) days after injection. Groups of neutrophils (N) or neutrophils and macrophage-like cells (M) were observed in the peritoneal cavity after injection. Some cells are joined by cytoplasmic extensions (blue arrow). A, Hemacolor; B, C. Peroxidase staining. Bar, $10 \mu \mathrm{m}$.

Fig. 6. Heat map displaying hierarchical clustering of DEG involved in apoptosis. Data are from fish injected with antigen (Ant), or with antigen plus adjuvant (Alhydrogel [Al], Freund's [FCA], Matrix-Q [MQ] or microspheres [Mic]), on days 1, 3 and 5 after injection. Results are expressed as mean expression ratio (log2- of different groups vs PBS). Different colours indicate upregulation (red) or downregulation (green).

Fig. 7. Heat map displaying hierarchical clustering of DEG related to lymphocyte migration and lymphocyte activity. Data are from fish injected with antigen (Ant), or with antigen plus adjuvant (Alhydrogel [Al], Freund's [FCA], Matrix-Q [MQ] or microspheres [Mic]), on days 1, 3 and 5 after injection. Results are expressed as 
mean expression ratio ( $\log 2$ - of different groups vs PBS). Different colours indicate upregulation (red) or downregulation (green).

Fig. 8. Heat map displaying hierarchical clustering of DEG related to the inflammatory response. Data are from fish injected with antigen (Ant), or with antigen plus adjuvant (Alhydrogel [Al], Freund's [FCA], Matrix-Q [MQ] or microspheres [Mic]), on days 1, 3 and 5 after injection. Results are expressed as mean expression ratio (log2- of different groups vs PBS). Different colours indicate upregulation (red) or downregulation (green).

Fig. 9. Dendrogram showing the cluster hierarchy for fish injected with antigen or antigen plus adjuvant, taking into account all the DEG. Antigen (ANTIG), Matrix-Q (MAT-Q), Freund's adjuvant (FCA), microspheres (MICROS), Alhydrogel (ALUM); on days 1, 3 and 5 post injection.

Fig. 10. Serum antibody levels, determined by ELISA, generated by turbot injected with PBS, Philasterides dicentrarchi membrane antigen (Ant) or antigen plus microspheres (Mic), Alhydrogel (AL), Matrix-Q (MQ) or Freund's adjuvant (FCA). The results are expressed in chemiluminiscence units and values shown are means \pm standard error ( $\mathrm{n}=10$ fish per group). Groups indicated by different letters $(\mathrm{a}-\mathrm{d})$ differ significantly $(\mathrm{p}<0.05)$.

\section{Supplementary figures}

Fig. S1. Silver-stained SDS-PAGE gel of $P$. dicentrarchi membrane proteins run under non-reducing conditions. Lane M, molecular markers in kDa.

Fig. S2. Heat map displaying hierarchical clustering of all DEG. Data are from fish injected with antigen (Ant), or with antigen plus adjuvant (Alhydrogel [Al], Freund's [FCA], Matrix-Q [MQ] or microspheres [Mic]), on days 1, 3 and 5 after injection. Results are expressed as mean expression ratio (log2- of different groups vs PBS). Different colours indicate upregulation (red) or downregulation (green).

Fig. S3. List of pathways with DEG based on Kyoto Encyclopedia of Genes and Genomes (KEGG) analysis. Results are shown for DEG in all groups of vaccinated fish.

Fig. S4. Dendrogram showing the cluster hierarchy for fish injected with antigen or antigen and adjuvant, taking into account all DEG related to cytoskeleton organization. Antigen (ANTIG), Matrix-Q (MAT-Q), Freund's adjuvant (FCA), microspheres (MICROS), Alhydrogel (ALUM), on days 1, 3 and 5. 
Fig. S5. Dendrogram showing the cluster hierarchy for fish injected with antigen 788 or antigen and adjuvant, taking into account all DEG related to apoptosis. Antigen 789 (ANTIG), Matrix-Q (MAT-Q), Freund's adjuvant (FCA), microspheres (MICROS), 790 Alhydrogel (ALUM), on days 1, 3 and 5 post injection.

791

792

793 Supplementary table

794

Table S1. Gene-specific primers used in Q-PCR assays.

795

796

797 


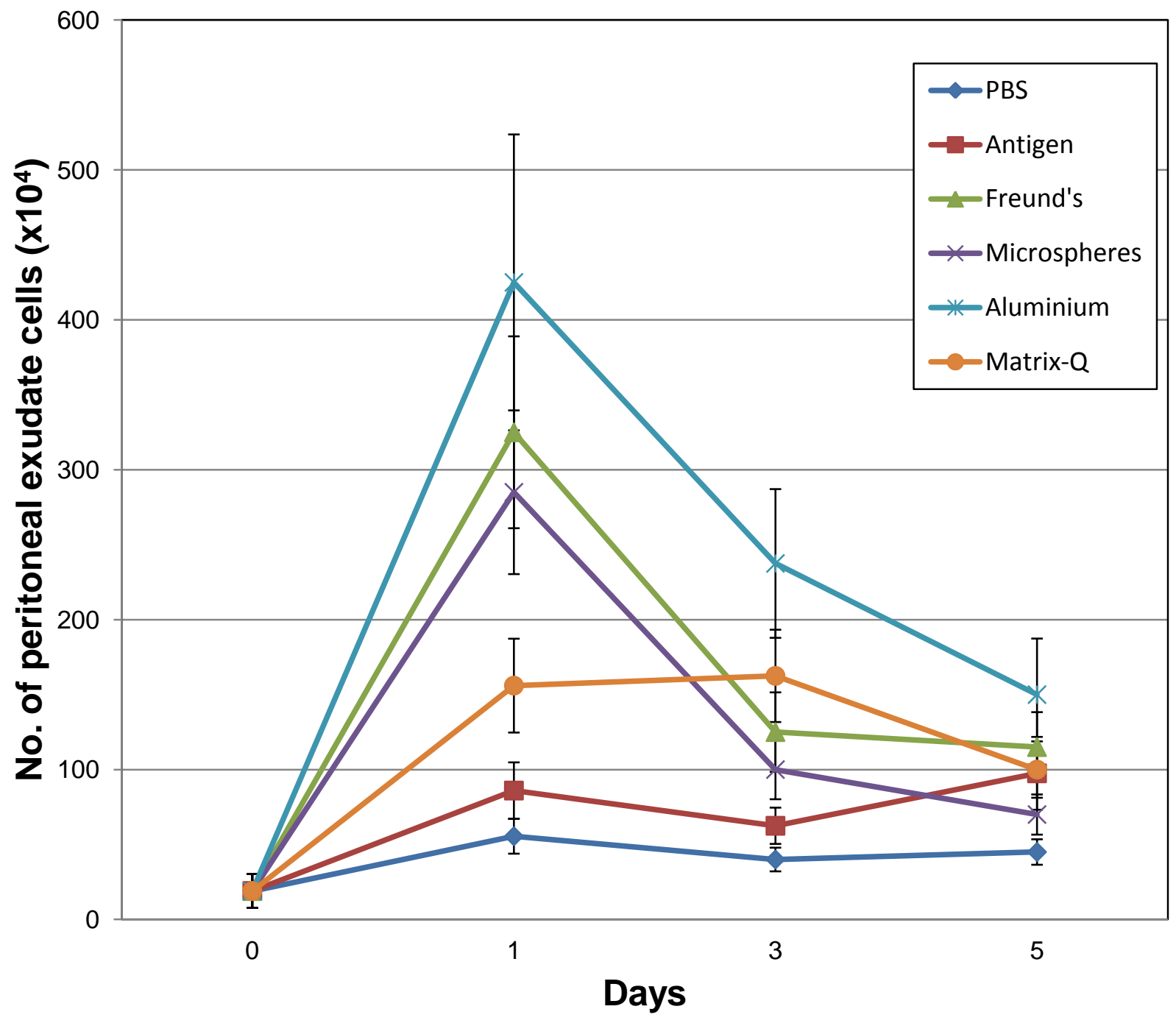

Fig. 1 


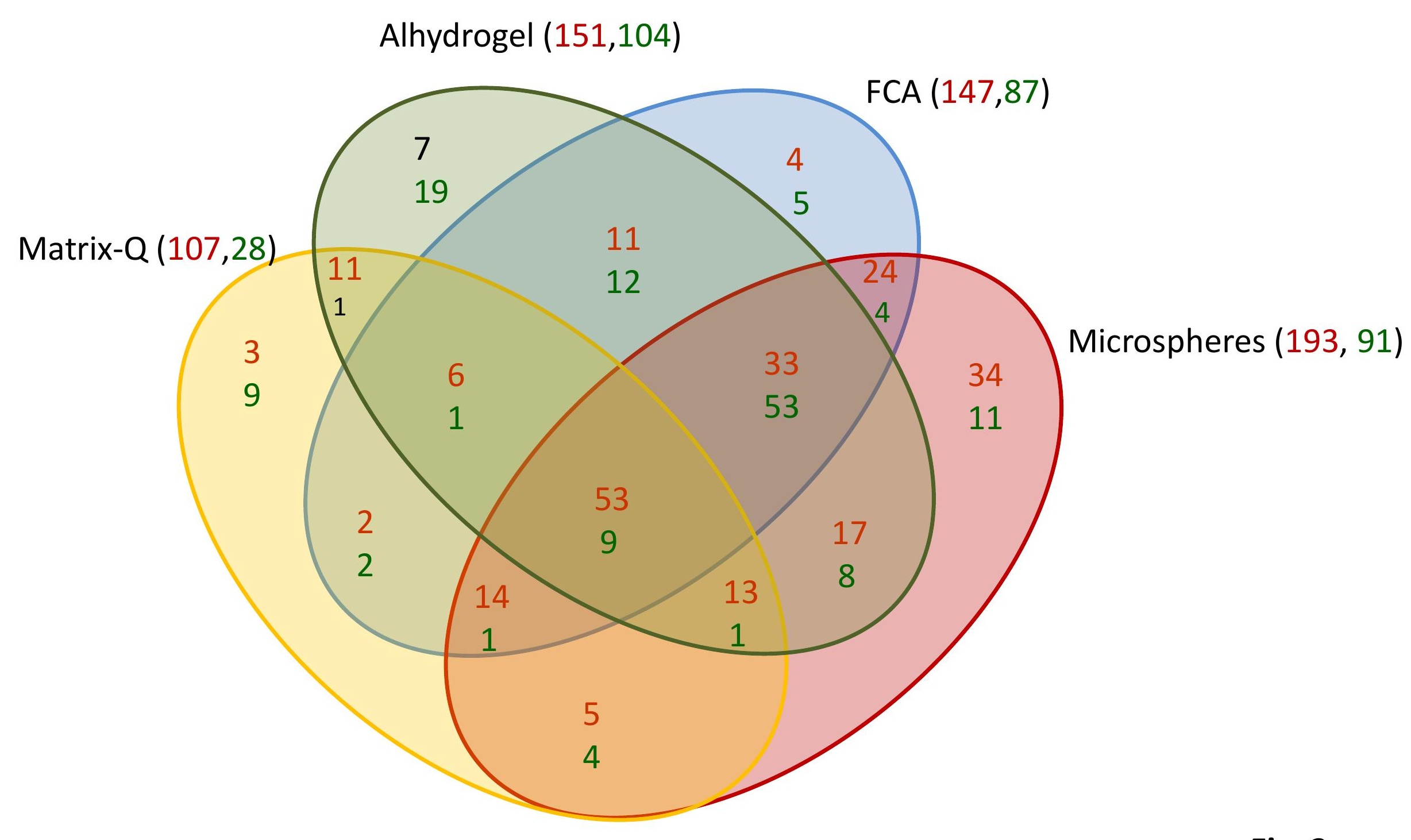

Fig. 2 


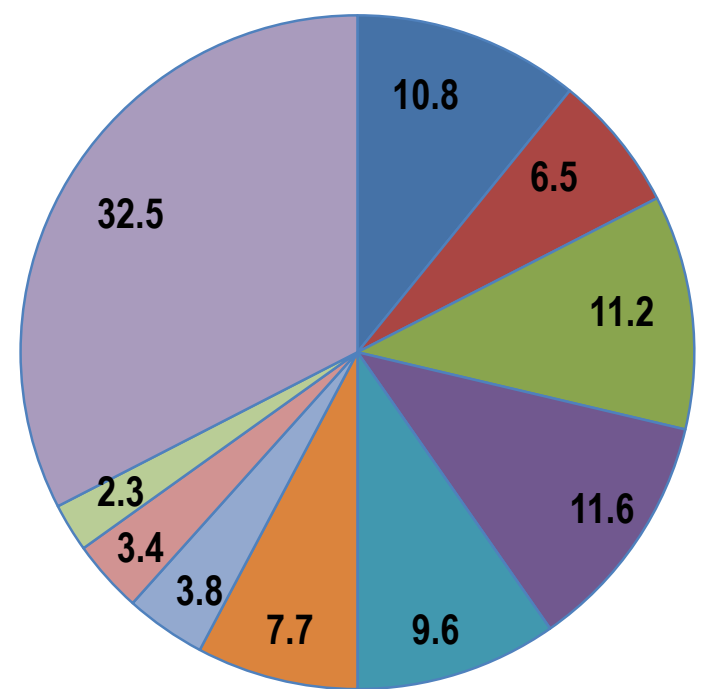

Aluminium

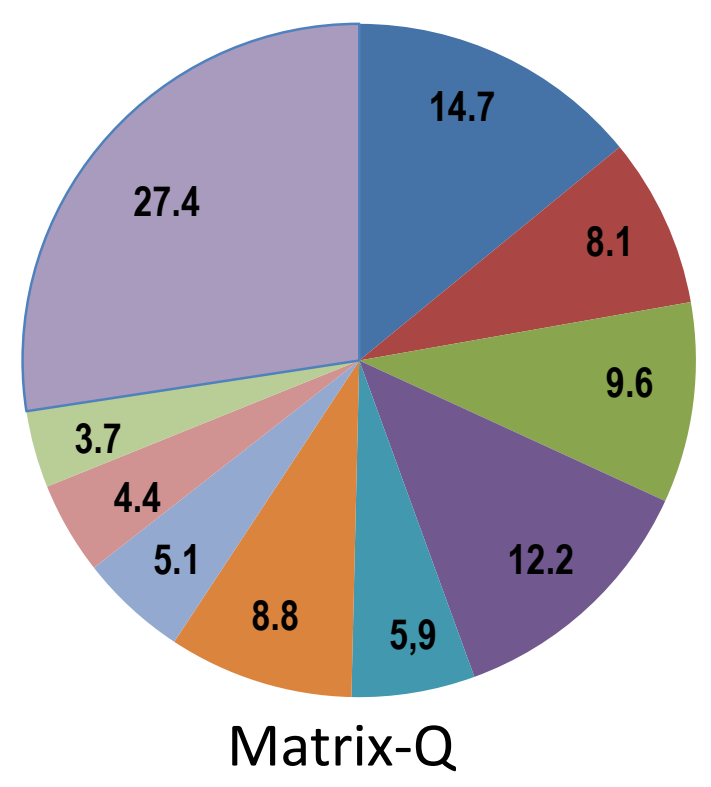

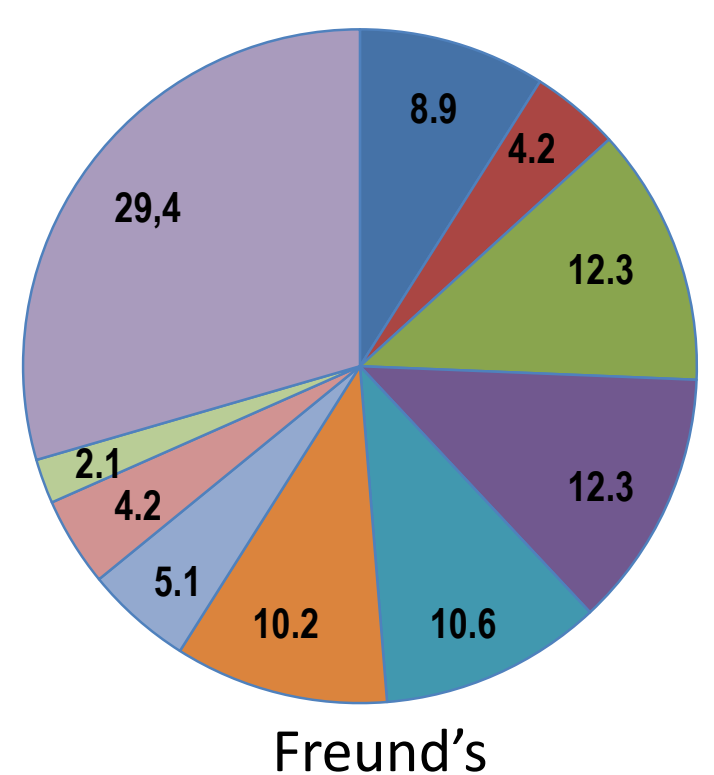

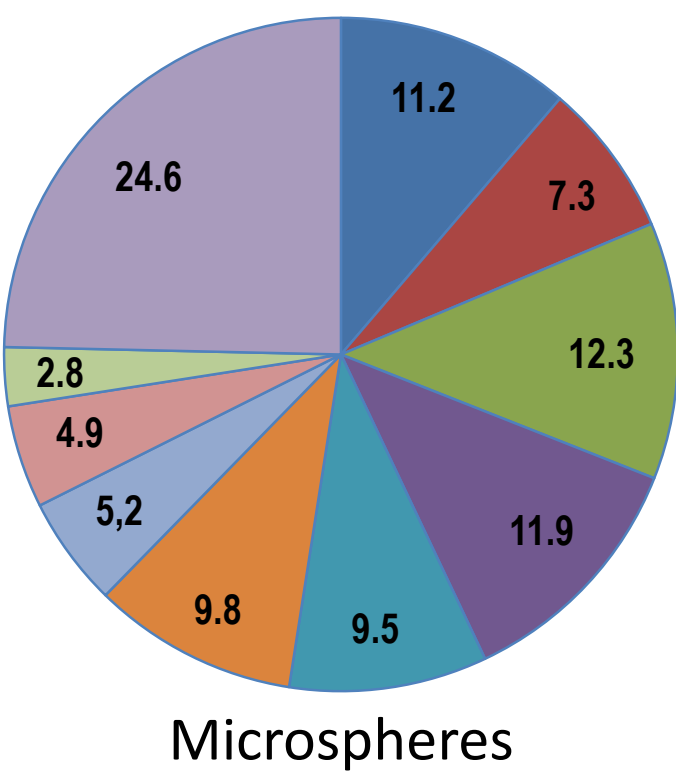

- Cell adhesion

- Cytoskeleton

$\square$ Cell surface receptor

- Cell proliferation

Immune response

$\square$ Cell death

$\square$ Cell migration

$\square$ Inflammatory response

$\square$ Angiogenesis

$\square$ Other

Fig. 3 
Figure 4
Click here to download high resolution image

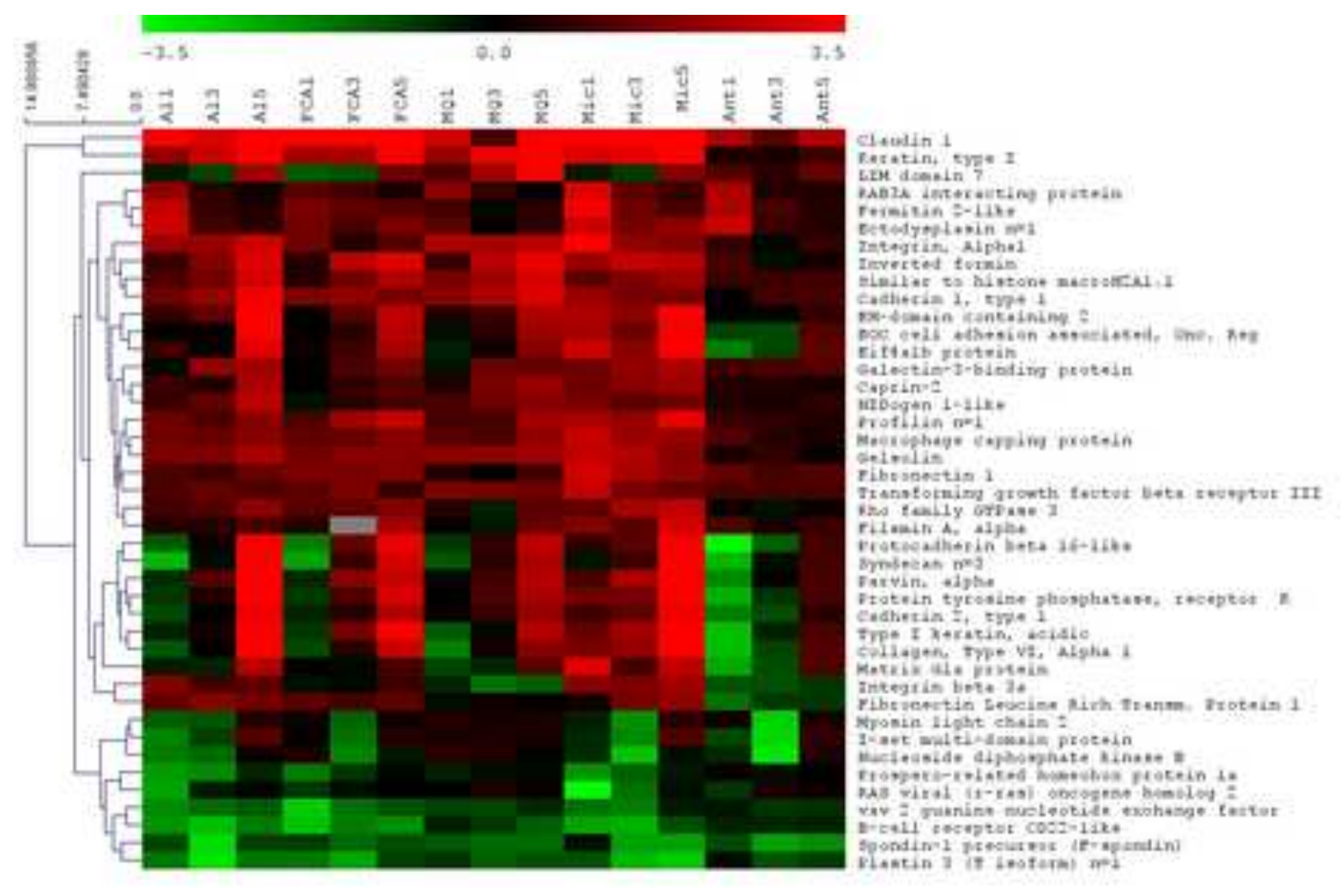



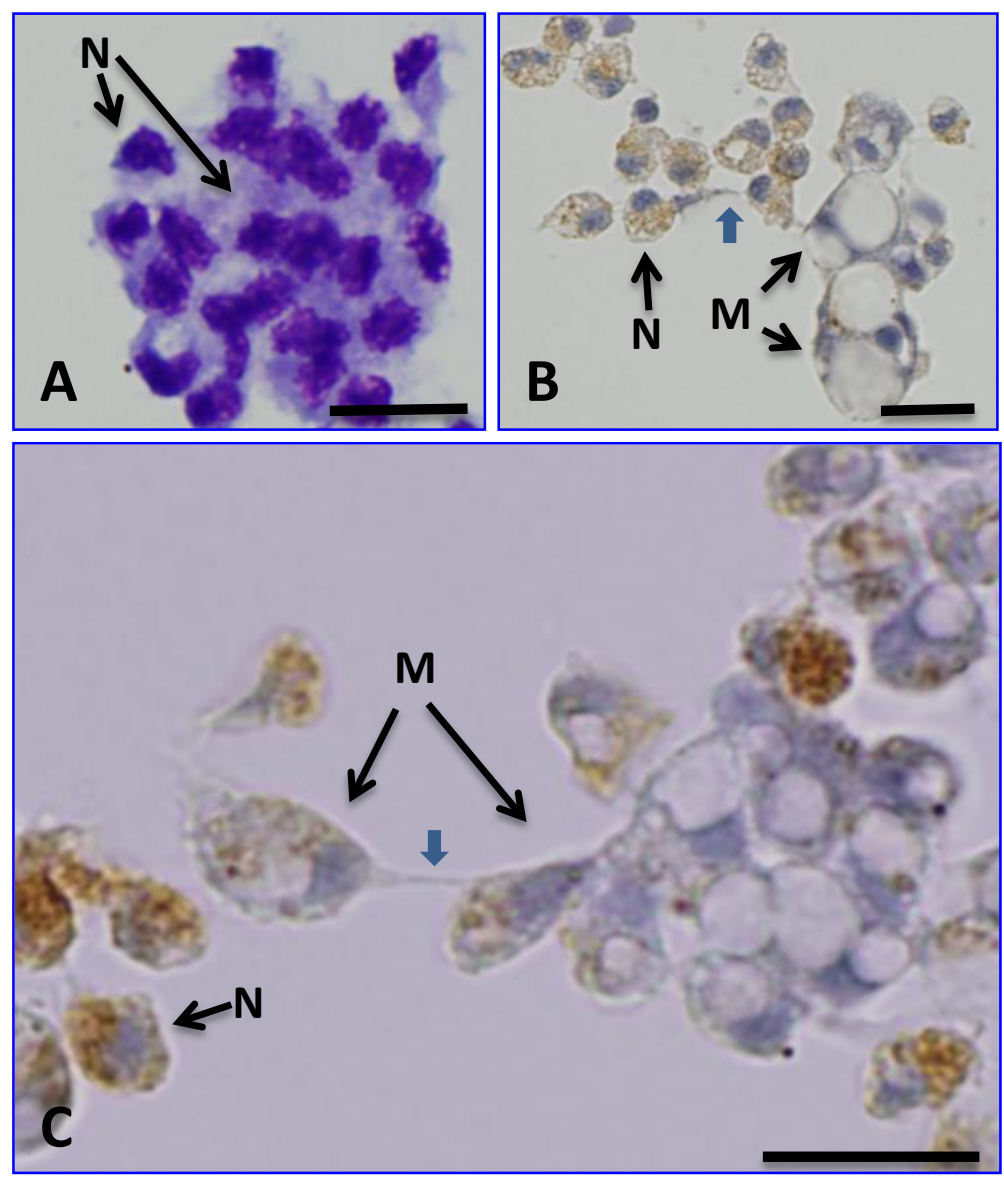

Fig. 5 


\section{Figure 6}

Click here to download high resolution image

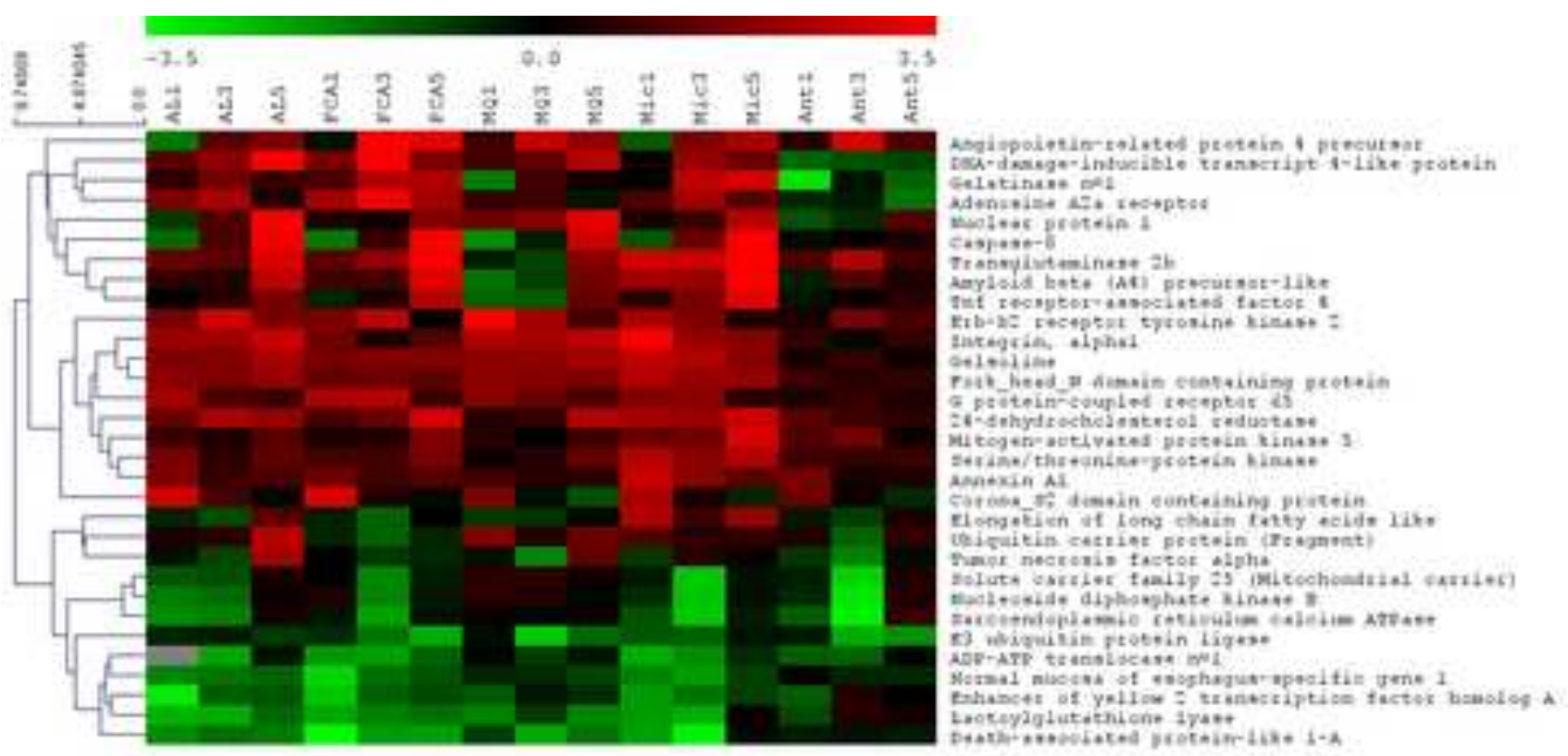


Figure 7
Click here to download high resolution image

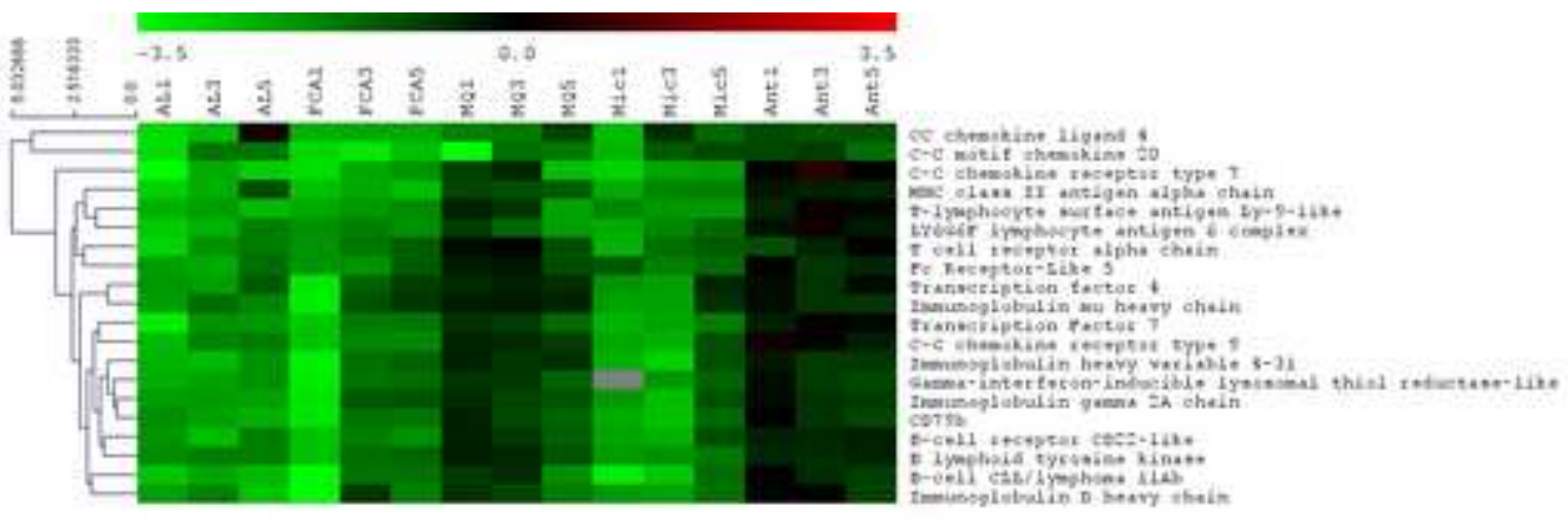

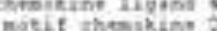

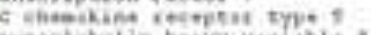

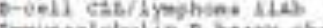


Figure 8
Click here to download high resolution image

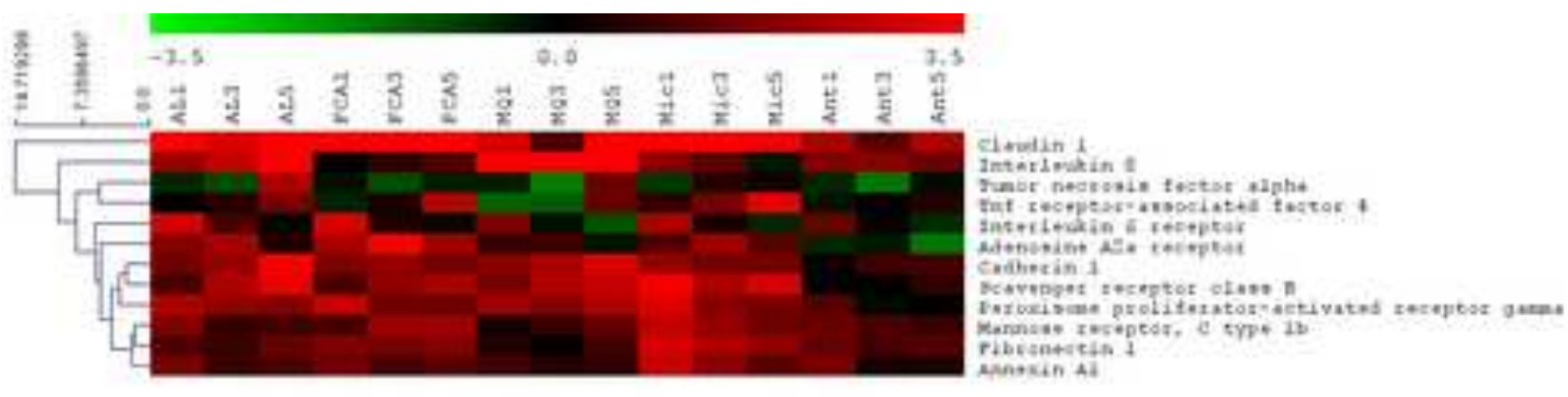




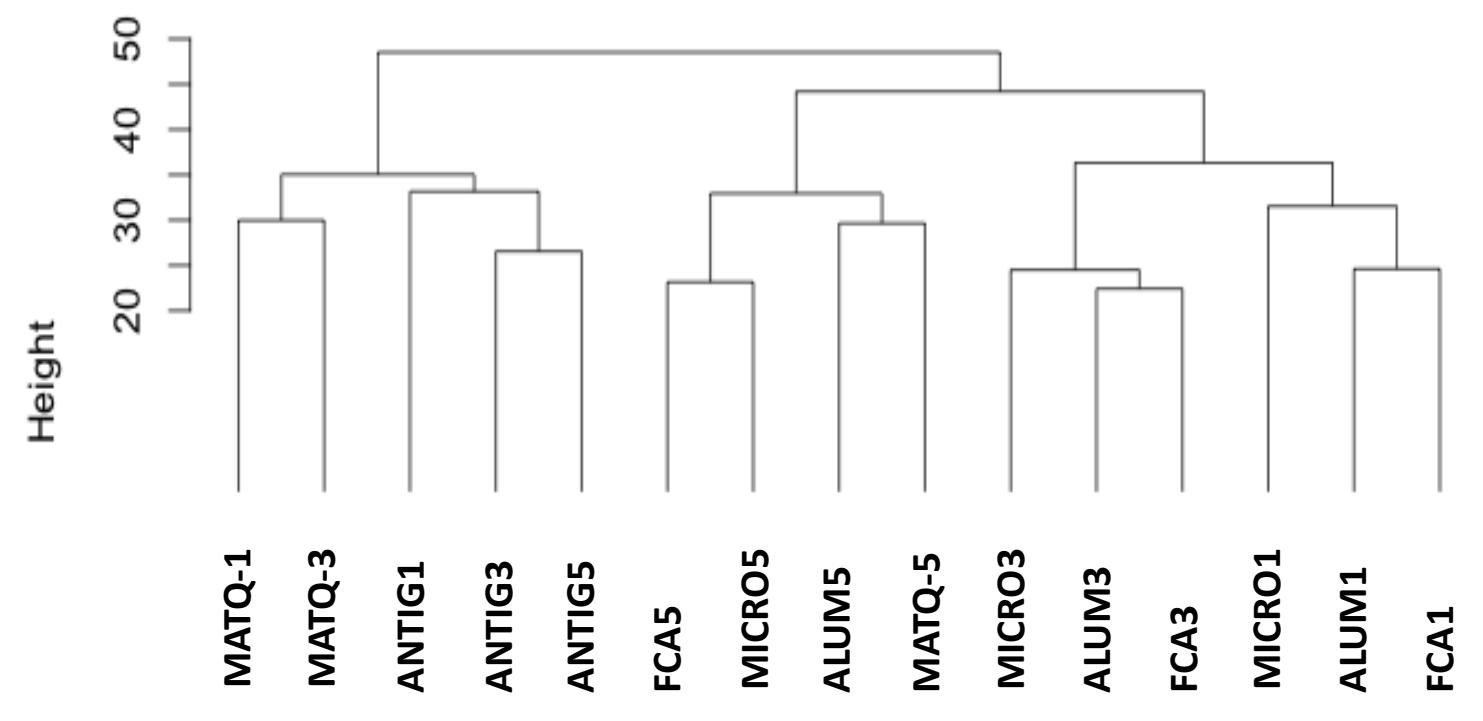

Fig. 9 
Figure 10

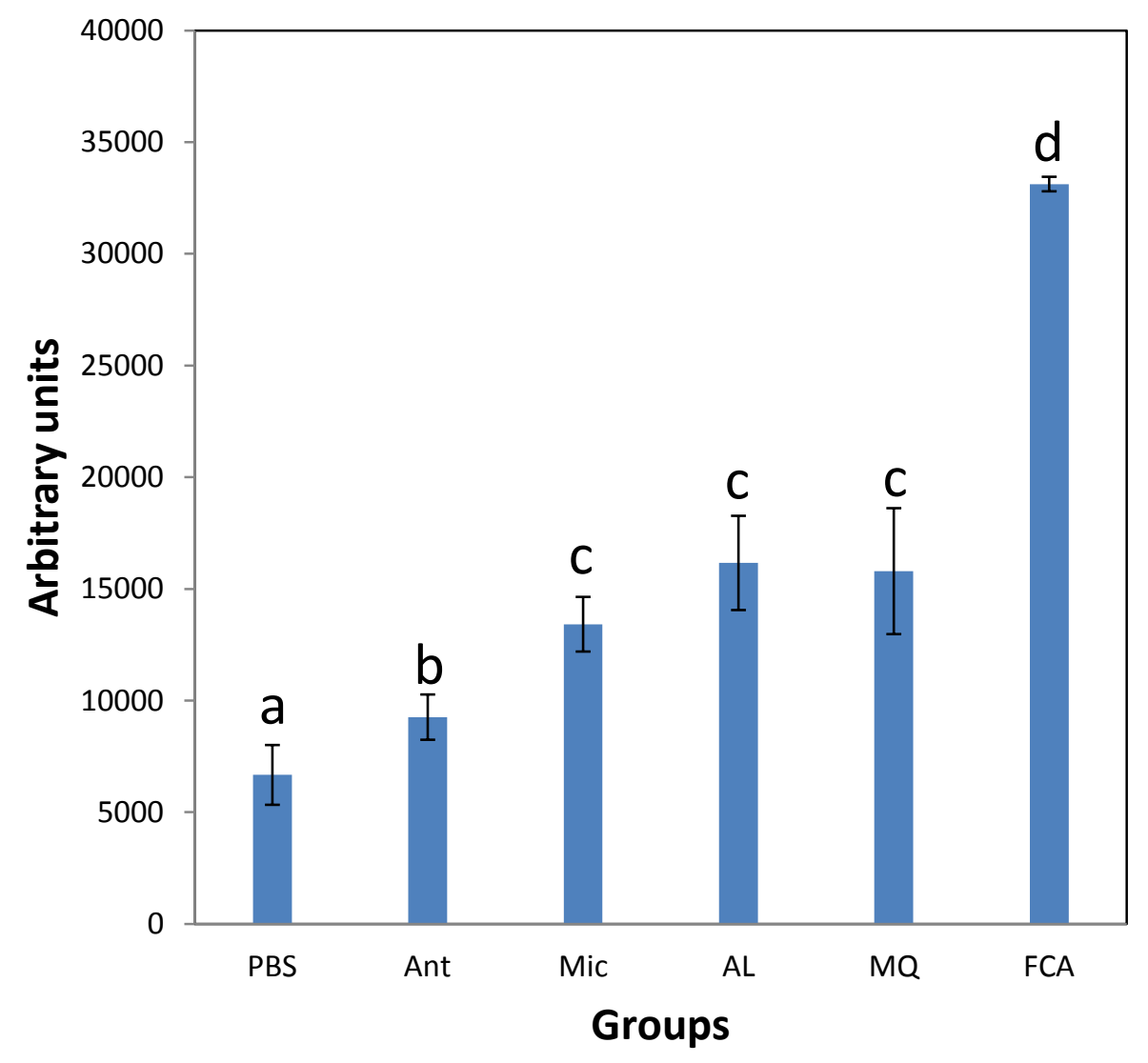

